\title{
DIFFERENCIATION FONCTIONNELLE DE LIGNEES PRIMAIRES ET PERMANENTES DE GRANULOSA DE BREBIS ET DE TRUIE
}

Mulsant P'., Hatcy 1. , Bonnet A., Benne $\Gamma$., Gasser $\mathrm{I}$.

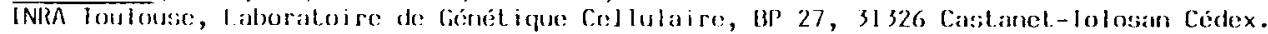

Nous abordons les mécanismes hormonodépendants contrôlant le développement du follicule ovarien par l'étude in vitro de cellules de la granulosa. Les réponses fonctionnelles de primocultures de brebis ou de truie et de lignées de brebis pérennisées par les gènes précoces de SV40 ont été comparées. Les effets des hormones gonadotropes (FSH, LH, PMSG) et d'agents mimétiques (dibutyryl AMP cyclique, forskoline, toxine cholérique) ont été testés à confluence, en milieu chimiquement défini. Pour la production de progestérone (dosage par HPLC ou RIA dans le milieu de culture), les primocultures de brebis sont fortement stimulees par l'AMPc et les activateurs de l'adenylate cyclase $(\times 10-\times 100)$ alors que pour la truie on observe également un haut niveau de sensibilité aux hormones gonadotropes (X20 - X100). Les lignées pérennisées de brebis subissent une forte extinction fonctionnelle, de 100 fois ou plus, de la production basale de la progestérone mais restent inductibles pour ce critère par l'AMPc.

La synthèse des protéines a été analysée, après marquage à la méthionine ${ }^{35} \mathrm{~S}$, par électrophorèse monodimensionnelle. Les protéines intracellulaires des primocultures et des clones pérennisés de brebis sont modifiées en réponse à l'AMPc et à la forskoline (notamment, induction d'une bande à 40 kd environ et répression à $25 \mathrm{kd}$ environ). Certaines protéines sécrétées dans le milieu de culture par les clones pérennisés sont induites par les mêmes effecteurs (à environ 80 et $130 \mathrm{kd}$ ). Chez la truie, les mêmes types de réponse sont également observés pour les protéines intracellulaires, après traitement aux hormones gonadotropes.

En conclusion, on observe un parallélisme dans les réponses aux effecteurs utilisés en ce qui concerne les deux indicateurs fonctionnels étudiés chez la brebis et la truie. La granulosa de brebis présente in vitro une sensibilité aux hormones gonadotropes beaucoup plus taible que celle de truie. Nous montrons aussi l'intérêt des lignées pérennisées dans cette étude puisqu'elles conservent certaines caractéristiques fonctionnelles des cellules d'origine.

\section{6}

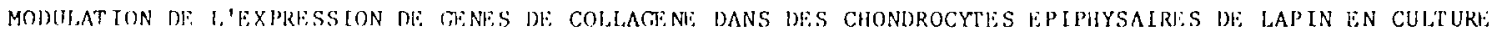

Nataf V., Tsag, ris L., Ronaventure J.*, Corvol M.T.

INSI:RM U. 3n, *INSi:RM U. 12, llopltal des Finfants-Malades, 75015 PARIS.

Des chondrocytes de cartilage éplphysalre de lapin prépubère mis en culture primalre dans un milleu Dulbecco-10 \% sérum se développent en colonies multicouches, synthétlsent et secrétent des protéoglycanes et plusteurs types de collagène mesurés respectivement après incorporation de 35 ssulfure et de 3 H-proline, et analysés par électrophorèse en gel d'acrylamlde. Les protéoglycanes sont de type "cartliage" par comparalson avec les molécules extraltes de fragments cartllaglneux. Les collagènes analysés sont de plusleurs types: plus de $85 \%$ des protélnes collagéniques sont de type $\alpha_{1}$ II avec $3 \%$ de type $\alpha_{1}$ I- $\alpha_{2}$ II et $10 \%$ de cype $\alpha_{1}$ III. Lorsque les cellules sont incubées pendant 2 cycles cellulatres supplémentalres dans un milieu défini contenant FGF ( 10 ng/ml, on note une dimfnution stgnfficative de la synthèse protélque cotale avec réduction de 60 à $70 \%$ des protéoglycantes et de $80 \%$ des protélnes collagénfques néosynthétisées. L'addition d'1nsuline (1-5 $\mu \mathrm{g} / \mathrm{ml})$ ou $1 \mathrm{GF} /(1-20$ $\mathrm{ng} / \mathrm{ml}$ ) stimule les syntèses protélques qui attelgnent alors un niveau stinflatre à celui observé en présence de sérum. L'étude des RNA totaux cellulaires réallsée par Slot blot et Northeru blot à l'alde de sonde cnNA spéclflques les gènes de collagène de type II, I et II montre sous l'effet de FGF seul une réduction signfflcative du taux de inRNA des chafnes de type II et de type I alors que le taux des chatnes de type II l est malntenu et mêne un peu augmenté. Après addition d'IGF l, il y a augmentation préférentlelle des mRNA correspondant aux chaînes de type II alors que l'tunsullne stimule de façon unfforme les inRNA dos différentes chat nes collagénlques.

Fn conclusion FGF, insuline et $I G F$ aglssent de façon différente sur la crolssance et la différenclation de chondrocytes in vitro. Seul IGF, stinule préférentiellement l'expresslon du phénotype différenclé. 